\title{
NOTAS MARGINAIS SOBRE ADORNO E FREIRE
}

\author{
MARGINAL NOTES ON ADORNO AND FREIRE
}

NOTAS MARGINALES SOBRE ADORNO Y FREIRE

\author{
Adilson Cristiano Habowski ${ }^{\mathrm{I}}$ \\ ELAINE CONTE II \\ 'Universidade La Salle/UNILASALLE, Canoas/RS - Brasil \\ IIUniversidade La Salle/UNILASALLE, Canoas/RS - Brasil
}

RESUMO O trabalho propõe uma análise do exílio, enriquecida pela requintada crítica de Theodor Adorno e Paulo Freire, em meio à ordem autoritária dos discursos vigentes da vida em sociedade. A pesquisa busca uma reversão do sentido comum de movimentos conservadores, ditatoriais e totalitários (marcados pelo emprego das forças armadas) da contemporaneidade, a partir de notas marginais de Adorno e Freire. A hipótese aqui defendida inclui uma revisão do papel da educação em contextos de exílios, capaz de ultrapassar os limites da desinformação humana operada unilateralmente e da cultura enquanto mercadoria, em função de uma valorização do conhecimento que passa pela autocrítica do processo de emancipação social. Diante das explorações, das injustiças sociais e da rigidez do pensar em diferentes contextos de exílio, Adorno e Freire escrevem potentes críticas à razão instrumental e ao mascaramento ideológico das sociedades dependentes e usurpadas de percepção, racionalidade e sensibilidade humana. Nesse processo, compreende-se, com Adorno, que a educação passa pela reavaliação crítica da cultura e pela reeducação da sociedade administrada, para superar o estado de opressão e alienação cultural. Por sua vez, Freire, defende uma pedagogia da autonomia capaz de emancipar, por meio do (re) conhecimento dialógico. Trata-se de uma exigência para a recriação da realidade sociocultural, seguindo as prerrogativas da autonomia solidária, liberdade, autoridade e dignidade humana imanente ao ato pedagógico. Embora distintas, concluímos que tais concepções sinalizam para um movimento participativo da cultura e de resistência crítica ao pensamento homogeneizador, no sentido de despertar e promover o diálogo que revigora a experiência formativa e criadora da educação.

Palavras-chave: EducaÇão; Exílios; Diálogos; EmancipaÇão. 
ABSTRaCr The work proposes an analysis of exile, enriched by the exquisite criticism of Theodor Adorno and Paulo Freire, amid the authoritarian order of the current discourses of life in society. The research seeks a reversal of the common sense of conservative, dictatorial and totalitarian movements (marked by the use of the armed forces) of contemporaneity, from marginal notes by Adorno and Freire. The hypothesis defended here includes a review of the role of education in contexts of exiles, capable of exceeding the limits of unilaterally operated human disinformation and culture as a commodity, due to an appreciation of knowledge that passes through the self-criticism of the process of social emancipation. Faced with the explorations, social injustices and the rigidity of thinking in different contexts of exile, Adorno and Freire write powerful criticisms of the instrumental reason and the ideological masking of societies dependent and usurped by perception, rationality and human sensitivity. In this process, it is understood, with Adorno, that education goes through the critical revaluation of culture and the reeducation of the administered society, to overcome the state of oppression and cultural alienation. Freire, defends a pedagogy of autonomy capable of emancipating, through dialogical (re)knowledge. It is a requirement for the recreation of the sociocultural reality, following the prerogatives of solidarity autonomy, freedom, authority and human dignity immanent to the pedagogical act. Although distinct, we conclude that such conceptions signal to a participatory movement of culture and critical resistance to homogenizing thinking, in order to awaken and promote dialogue that strengthens the formative and creative experience of education.

Keywords: Education; Exiles; Dialogues; Emancipation.

Resumen La obra propone un análisis del exilio, enriquecido por la exquisita crítica de Theodor Adorno y Paulo Freire, en medio del orden autoritario de los discursos actuales de la vida en la sociedad. La investigación busca una reversión del sentido común de los movimientos conservadores, dictatoriales y totalitarios (marcados por el uso de las fuerzas armadas) de la contemporaneidad, de las notas marginales de Adorno y Freire. La hipótesis defendida aquí incluye una revisión del papel de la educación en contextos de exiliados, capaces de superar los límites de la desinformación humana operada unilateralmente y la cultura como una mercancía, debido a una apreciación del conocimiento que pasa a través de la autocrítica del proceso de emancipación social. Frente a las exploraciones, las injusticias sociales y la rigidez del pensamiento en diferentes contextos de exilio, Adorno y Freire escriben poderosas críticas a la razón instrumental y al enmascaramiento ideológico de las sociedades dependientes y usurpadas por la percepción, racionalidad y sensibilidad humana. En este proceso, se entiende, con Adorno, que la educación pasa por la revalorización crítica de la cultura y la reeducación de la sociedad administrada, para superar el estado de opresión y alienación cultural. Freire, defiende una pedagogía de autonomía capaz de emanciparse, a través del conocimiento dialogical. Es un requisito para la recreación de la realidad sociocultural, siguiendo las prerrogativas de la solidaridad autonomía, libertad, autoridad y dignidad humana inmanente al acto pedagógico. Aunque distintas, llegamos a la conclusión de que tales concepciones señalan un movimiento participativo de cultura y resistencia crítica al pensamiento homogeneizador, con el fin de despertar y promover el diálogo que fortalezca la experiencia formativa y creativa de la educación.

Palabras Clave: Educación; Exiliados; Dí́logos; Emancipación. 


\section{INTRODUÇÃo}

O exílio engloba relações de poder entre histórias, tempos, espaços, identidades e memórias, perpassando por biografias atingidas pela ruptura de processos vitais estimuladas por traços disciplinadores e padrões autoritários, que não aceitam divergências da ordem do discurso em voga (JENSEN; PARADA, 2019). Muitos são os que fazem parte da galeria ${ }^{1}$ de sujeitos que se deslocaram de seu país de origem, na maioria das vezes, por questões ideológicas, sociais e políticas, um fenômeno recente de retirada de liberdade pela força de ameaças e retirada de direitos humanos. Nesse contexto, vale assinalar os exemplos recentes de perseguição e intimidação sofridas por Débora Diniz, ${ }^{2}$ antropóloga, pesquisadora do Grupo Temático Bioética da Abrasco e professora da Universidade de Brasília porque ajudou a encaminhar a permissão do aborto em gestações de fetos anencéfalos, além de ser idealizadora de uma ação no Supremo Tribunal Federal sobre a descriminalização do aborto até a $12^{\mathrm{a}}$ semana de gravidez. Pelo fato de sua pesquisa e trabalho se chocarem com as políticas de governo, Débora Diniz foi vítima de linchamento nas redes sociais, recebendo ameaças de morte, a ponto de ser inerida no Programa de Proteção aos Defensores de Direitos Humanos do Governo Federal, sendo aconselhada a deixar o país.

Soma-se o caso da filósofa Márcia Tiburi, ${ }^{3}$ candidata ao governo do Estado do Rio de Janeiro, professora universitária, artista plástica e escritora, que deixou o Brasil também por ameaças, optando pelo autoexílio. Em entrevista ao Jornal Valor declarou os motivos que a levaram a encarar o autoexílio: Sai porque estava com muito medo das ameaças, do que estava ocorrendo com o Brasil e do que estava ocorrendo comigo. Nas redes você encontra muita gente dizendo que vai me matar, que vai dar um tiro em mim, que vai acabar comigo. Também vinham ameaças diretamente por e-mail, SMS, WhatsApp. Fui colocada num grupo com dez caras sinistros que tinha uma foto do Bolsonaro com uma faca. Também recebia ameaças na rua. Não podia mais sair de casa, ir à farmácia, ir a uma padaria. Chega um desconhecido, esbarra e diz: Eu sou fascista com muito orgulho, você se cuide. Um outro se aproxima e fala: Cuidado, na próxima vez que eu te encontrar eu acabo com você. Já estava inscrita em um programa que oferece acolhida e segurança a escritores ameaçados ao redor do mundo, o City of Asylum.

Ainda, Jean Wyllys, político, escritor e professor universitário, se tornou um dos mais conhecidos políticos da esquerda do país, e o único legislador abertamente homossexual no Congresso brasileiro. Em novembro de 2018, a Comissão Interamericana de Direitos Humanos da Organização dos Estados Americanos (OEA) ordenou providências para a

1 No atual contexto brasileiro, muitos pensadores, filósofos e políticos deixaram o país após a eleição de Jair Messias Bolsonaro, pelos ataques violentos sofridos e abuso de autoridade, principalmente nas redes sociais. Entre os mais conhecidos, citamos os casos de Débora Diniz, Marcia Tiburi e Jean Wyllys. A professora Débora deixou o Brasil em 2018, assim como a filósofa Márcia e Jean Wyllys, em dezembro de 2018. Esse movimento de saída de grandes intelectuais do Brasil e busca de alternativas de trabalho em outros países vem crescendo nos últimos tempos, dada a condição de retirada de direitos, desvalorização do conhecimento, aumento da exclusão social, semiformação e subempregos.

2 Notícia do jornal El País, disponível em: http://brasil.elpais.com/brasil/2019/02/22/politica/1550871025 250666.html. Acesso em: 18 dez. 2019.

3 Notícia do Jornal Valor, disponível em: https://valor.globo.com/politica/noticia/2019/03/11/marcia-tiburi-relata-ameacas-e-deixa-o-pais.ghtml Acesso em 19 dez. 2019. 
proteção a Jean Wyllys por parte do Governo Federal, diante das ameaças de morte ao parlamentar. Nas eleições de 2018 foi reeleito para o terceiro mandato, entretanto, decidiu não tomar posse, renunciando ao cargo e exilando-se em Berlim.

De acordo com as provocações de Jensen e Parada (2019, p. 406), o exílio tem seu início "na velha prática do banimento, mas os exilados sem pátria são uma criação do Estado do século XX". Contudo, o aparecimento numeroso de exilados é uma questão travada pelas consecutivas crises políticas, ideológicas e militares das primeiras décadas do século $\mathrm{XX}$, de modo que identificamos inúmeros refugiados, homens, mulheres e crianças, que se movem no cenário atual sendo parte das configurações do mundo contemporâneo (JENSEN; PARADA, 2019). Edward Said (2003, p. 46), no ensaio Reflexões sobre o exílio, trata e discute o tema de modo enriquecedor, abordando a partir de diferentes aspectos. Suas reflexões se voltam, inicialmente, para o fato de que o exílio não é uma questão de escolha, sendo necessário distinguir o exílio dos outros modos de afastamento da terra de origem. No entanto, ser expulso de sua terra de origem e proibido de retornar é o que define a condição de exilado. "O sujeito exilado sai sem saber se retorna à sua pátria. Seu projeto político e de vida foi derrotado, e, a partir desse dado, ele poderá ou não se reinventar no exterior, ou simplesmente desistir" (JENSEN; PARADA, 2019, p. 408). Além disso:

\footnotetext{
O exílio nos compele estranhamente a pensar sobre ele, mas é terrível de experienciar. Ele é uma fratura incurável entre um ser humano e um lugar natal, entre o eu e seu verdadeiro lar: sua tristeza essencial jamais pode ser superada. E, embora seja verdade que a literatura e a história contêm episódios heróicos, românticos, gloriosos e até triunfais da vida de um exilado, eles não são mais do que esforços para superar a dor mutiladora da separação. As realizações do exílio são permanentemente minadas pela perda de algo deixado para trás para sempre (SAID, 2003, p. 46).
}

Se formos olhar o contexto da Segunda Guerra Mundial (1939 a 1945), período em que o totalitarismo nazista conduziu a sociedade alemã à submissão de um ditador fascista, observamos que a humanidade chegou ao ápice da barbárie (Holocausto), tornando-se indiferente à dor e ao sofrimento alheio pela banalidade de uma superioridade racial. Theodor Adorno (1903-1969), por sua voz crítica, inconformista e postura de vertente marxista de consciência do seu tempo, resistiu, com outros teóricos da Escola de Frankfurt, à atitude de adesão da sociedade alemã às atrocidades e ao descaso humano realizado pelo partido nazista. Por isso, o exílio foi o caminho encontrado para não permitir o perecimento de sua voz crítica, revolucionária e de resistência à normatividade da época. Adorno e Freire experienciaram o exílio em locais, períodos, contextos e conjunturas diferentes, mas por viverem e compreenderem tal experiência, da qual fizeram parte, desenvolveram suas críticas contra regimes totalitários, advertindo sobre o poder de dominação, manipulação e homogeneização das massas e a identificação cega aos coletivos. Entendemos que ambos apontaram críticas contundentes contra a barbárie humana em conjunturas ditatoriais, provocando resistência às ideias hegemônicas de governo e que devem ser indagadas e ressignificadas no contexto atual.

A Ditadura Militar (1964-1985), no Brasil, representou um período de repressão, perseguição política e censura às posturas socialistas, de esquerda e que defendiam o direito 
de liberdade e igualdade social. Nesse contexto, os interesses dos militares não estavam em consonância com as necessidades do povo oprimido, mas dos burgueses brasileiros que detinham o poder econômico e se perpetuaram no governo. Os que se mostraram críticos a essa conjuntura opressiva e com olhos voltados aos mais explorados sofreram pelas suas posturas, sendo torturados, presos, condenados à morte ou sendo exilados em outros países. Paulo Freire (1921-1997) foi um dos educadores críticos de vertente socialista, que após algumas prisões porque estava preocupado em desenvolver um programa de alfabetização de adultos no país não teve alternativa exceto o exílio. ${ }^{4}$

Adorno e Freire, ainda que procedentes de conjunturas distintas, exprimem afinidades nos modos críticos de ver, pensar, sentir e habitar o mundo, sendo arquétipos de resistência e de ações reflexivas e revolucionárias de exilados que resistiram a contextos opressivos e totalitários, em defesa de uma educação humanizadora e de luta contra as barbáries. Nessa perspectiva, Adorno passou pela experiência do Holocausto e Freire pela Ditadura Militar, de modo que a experiência de exilados provocou repercussões em seus países de origem e nos países em que se exilaram, gerando influências em outras gerações para além de seus países de origem. Ainda que dolorida a experiência de exilado, em tempos de conflitos políticos e guerra possa ser, é preciso tomar ciência que ela proporciona uma ruptura de barreiras e fronteiras que prendem e aprisionam o sujeito em sua própria pátria. Quando Adorno e Freire foram exilados, o ambiente solitário e hostil tornou-se a possibilidade de tomada de distância do território dominado, concedendo assim uma análise crítica mais profunda dos contextos em questão.

Frente às posturas dos dois intelectuais que tiveram o exílio como refúgio e caminho de manterem vivas suas posturas críticas, este ensaio tem a seguinte problematização: quais as similaridades e cânones na formação intelectual dos críticos Theodor Adorno e Paulo Freire que foram exilados de suas pátrias por regimes totalitários? A pesquisa tem seu alicerce na abordagem hermenêutica reconstrutiva, que nos possibilita interpretar e compreender o exílio de Adorno e Freire como um desígnio do intelectual crítico frente a regimes totalitários, para pensar os destinos de uma educação que possa esclarecer as pessoas e prevenir barbáries coletivas. A aflição que decorre pela sobrevivência e a situação angustiante de retorno se constitui em "um campo de estudos que radicaliza o compromisso ético dos historiadores e cientistas sociais com seu presente. A mobilização de testemunhos como fonte para a pesquisa e a atenção para as trajetórias individuais e coletivas em um contexto de reconstrução são problemas analisados" (JENSEN; PARADA; 2019, p. 408).

Trata-se de compreender, pela via hermenêutica reconstrutiva, os contextos dos exílios dos dois pensadores que foram desterrados pelas suas posturas consideradas hostis e de implicações nefastas diante dos modelos centralizadores, inclusive dos sistemas de ensino da memória cultural da época. A abordagem hermenêutica reconstrutiva volta-se para a compreensão dos textos e discursos, considerando o sujeito descentrado pela relação com o outro no agir comunicativo voltado ao consenso (HABERMAS, 1987). Nessa perspectiva de análise, o mundo da vida requer um processo de reflexão crítica e validação das abor-

4 Entre outros motivos caluniosos para a perseguição política de Freire estava o fato de que esse professor seria um "perigoso subversivo internacional, um inimigo do povo brasileiro e um inimigo de Deus". Palestra proferida por Freire e disponível em: http://www.youtube.com/watch?v=HlJjgljUj38. Acesso em: 29 nov. 2018. 
dagens, das forças ideológicas, sociais, econômicas e dos interesses técnicos a que foi formatada. Desse modo, o diálogo intersubjetivo surge como reação à hermenêutica tradicional que havia subsumido o outro na tradição (GAMBOA, 2008; DEVECHI; TREVISAN, 2010). Assim, "a hermenêutica reconstrutiva busca ir além dos propósitos da hermenêutica tradicional, porque busca não só compreender, mas validar as ações linguísticas diante do mundo comum a todos" (DEVECHI; TREVISAN, 2010, p. 154-155).

Para Habermas (1987), a hermenêutica reconstrutiva designa o procedimento de resgate de elementos da tradição, agora apresentados na perspectiva intersubjetiva e dialógica da linguagem, democratizando e reconstruindo o que era proposto por uma razão monológica. Entretanto, falta ainda a dimensão pedagógica da referência crítica das ideologias que pode atravessar os discursos situados no contexto histórico e necessitam da reflexão do intérprete sobre o aparato digital. Habermas (1987) afirma que vivemos um projeto de esclarecimento que ficou inacabado por interesses de dinheiro e poder, que aniquilou as necessidades de diálogo e interdependência com o outro. A hermenêutica reconstrutiva no contexto contemporâneo reside em reavivar o diálogo crítico com a tradição cultural, de resistência ao fenômeno de incomunicabilidade, dispersão e pulverização das informações, no sentido de gerar problematizações e reconstrução de textos, para que mergulhados no contexto, possamos analisar o fenômeno humano em sua complexidade.

Adorno (2003) não se enquadrou como hermeneuta, mas se movimentou por um processo hermenêutico sempre em busca constante e revisão de (con)textos sociais para chegar a uma realidade mais justa e interdependente das ações e planos humanos. Adorno (2003, p. 269) identifica caminhos no "detalhe a centelha hermenêutica" para uma relação dialética, a partir da qual se apresentam contradições e complementações, no próprio jogo conceitual da dinâmica histórica. Isto é, "rodeando os conceitos com outros conceitos em diferentes tentativas de formar constelações, até que a figura apareça (não um conceito)" fechado em si (MÜLLER, 2009, p. 71). A verdadeira interpretação não busca uma definição acabada e fixa, pois o significado "é incompleto, contraditório e fragmentário e grande parte dele pode estar entregue a cegos demônios. Talvez a leitura seja precisamente nossa tarefa, para que lendo aprendamos a conhecer melhor e a banir os poderes demoníacos" (ADORNO, 2005, p. 7).

Com base nos pressupostos de Freire (2002, p. 83), também buscamos realizar um diálogo emancipador, visto que a conversação é "encontro entre os homens, mediatizados pelo mundo, para designá-lo. Se ao dizer suas palavras, ao chamar ao mundo, os homens o transformam, o diálogo impõe-se como o caminho pela qual os homens encontram seu significado enquanto homens", então, o "diálogo é, pois, uma necessidade existencial". Tal diálogo é tido como um processo de abertura para a compreensão e valorização das diferenças e das múltiplas vozes, possibilitando o avanço interpretativo na conversação (auto) crítica. Freire (2006) observa que a capacidade de diálogo é a abertura para a inquietação e a curiosidade epistemológica, no sentido de aprender e evoluir com o outro, rompendo barreiras com a homogeneização das consciências. "Porque os sujeitos dialógicos não apenas conservam sua identidade, mas a defendem e assim crescem uns com os outros. O diálogo, por isso mesmo, não nivela, não reduz um ao outro. Nem é favor que um faz ao outro" (FREIRE, 2006, p. 118). É nesse sentido que a experiência de exílios faz brotar novas com- 
preensões para a dimensão política de dar voz ao outro, despertando novas reflexões, que são decorrentes da ação coletiva em processos circulares de cultura e de interdependência humana solidária.

Desse modo, o presente ensaio inicia com a historicidade do pensamento de Adorno ante seu exílio e, posteriormente, aborda as posturas críticas de Freire e as influências em sua caminhada. Em cada pensador, apresentamos também seus entendimentos sobre a educação, suas motivações investigativas, constituindo mais um elemento da coerência, no sentido de superar os regimentos totalitários. Como culminância, exibimos uma reflexão que subjaz a vida de ambos, uma vez que tiveram que se exilar para manterem posturas de resistência ao instituído, como vemos em exílios com êxodos populacionais e emigrações com deportações nas situações contemporâneas. Esse reconhecimento da condenação ao exílio pela opressão, expulsão e fuga é evidenciado por Arendt (1989, p. 347) como dilema da própria condição humana, em suas palavras, "não ter raízes significa não ter no mundo um lugar reconhecido e garantido pelos outros".

\section{A POSTURA CRÍTICA FRENTE AO TOTALITARISMo DAS FORMAS DE PENSAR}

Theodor Adorno, ${ }^{5}$ nascido em 1903 na cidade de Frankfurt, tornou-se ao longo de sua trajetória um crítico da sociedade capitalista e do sistema que conduz o pensar moderno. Sua formação de músico, psicólogo, sociólogo e filósofo contribuiu para um olhar global da sociedade. A influência kantiana, hegeliana, husserliana e marxista, na fundação da Escola de Frankfurt, em 1924, e na sede do Instituto de Pesquisa Social esteve atrelada a outros expoentes da filosofia como Max Horkheimer, Félix Weil e Herbert Marcuse.

É no contexto de Segunda Guerra Mundial (1939-1945) que o pensamento crítico de Adorno floresce e se revela consistente ante ao fato histórico que marca profundamente sua personalidade e pensamento crítico-social. Em busca de refúgio, em 1933, parte então à Inglaterra, onde lecionou na Universidade de Oxford. Horkheimer, que estava exilado nos Estados Unidos convidou Adorno para assumir a coordenação do Princeton Radio Research, em Nova York. Em 1938, Adorno mudou-se para os Estados Unidos, trabalhando no projeto musical e no Instituto de Pesquisa Social. O exílio vivenciado por ambos, imersos em uma conjuntura social de ruptura de padrões estabelecidos, fez brotar um campo de forças e novas interpretações de mundo, das diferenças, da alteridade e da própria condição humana. Além disso, permitiu a percepção crítica de que muitas das ações coletivas apresentadas no contexto totalitário do Holocausto não foram oriundas de uma postura pessoal e livre dos sujeitos, mas da imposição e manipulação oriunda de um sistema coercitivo.

5 Theodor Adorno, nascido em 1903 na cidade de Frankfurt, tornou-se ao longo de sua trajetória um crítico da sociedade capitalista e do sistema que conduz o pensar moderno. Sua formação de músico, psicólogo, sociólogo e filósofo contribuiu para um olhar completo da sociedade. A influência kantiana, hegeliana, husserliana e marxista, na fundação da Escola de Frankfurt, em 1924, esteve junto, com sede no Instituto de Pesquisa Social, ao lado de outros expoentes da filosofia como Max Horkheimer, Félix Weil e Herbert Marcuse e, posteriormente, acrescentando outros filósofos que muito contribuíram ao pensamento dessa escola. É a partir da Segunda Guerra Mundial (1939-1945) que o pensamento crítico de Adorno recebe grande destaque, fortemente marcado por esse fato histórico, uma vez que ele e outros companheiros da Escola de Frankfurt foram forçados ao exílio. 
Adorno e Horkheimer, em 1941, partem então para Los Angeles. Foi a partir do contexto de nazismo e do exílio, que juntos redigem sua principal obra, Dialética do Esclarecimento (1944), cunhando o termo de indústria cultural. Após dezesseis anos de exílio, Adorno e Horkheimer retornaram à Alemanha e reconstruíram o Instituto de Pesquisa Social em seus pedaços/fragmentos, uma vez que se encontrava destroçado e destruído.

É por meio de uma postura crítica e de contracultura ao mercado que surgem os saberes tornados problemáticos dos teóricos da Escola de Frankfurt, apontando críticas a esse sistema ideologizante de interpretações isoladas, alienantes e de condutas extremistas, cujos elementos ganham força pelas mídias. O conceito de indústria cultural é uma das principais contribuições de Adorno (1903-1969) e Horkheimer (1985-1973) para ajudar nas análises críticas das (re)produções e circulação dos produtos simbólicos culturais na sociedade do século XX. Outros conceitos como formação e semiformação também foram cunhados por eles e hoje passam por reconfigurações, tendo em vista as mediações culturais das tecnologias digitais em voga. A expressão teoria crítica ${ }^{6}$ é o alicerce principal e, portanto, ampla na sua acepção, pois nomeia todas as teorias que têm como pauta a negação da ordem estabelecida, de perspectiva antipositivista e contra-hegemônica, no anseio de uma sociedade justa, livre, sensível e humana.

É nesse contexto que, a partir da década de 1920, a Teoria Crítica se constitui em um grupo de pesquisadores marxistas não ortodoxos, que desenvolveram pesquisas e intervenções teóricas sobre as problemáticas filosóficas, culturais, econômicas, políticas, estéticos e sociais suscitadas pelo capitalismo da época e que influenciaram as ideias dos sujeitos (década de 40 a 70) do século XXI. A partir daí se constitui a chamada Escola de Frankfurt, ${ }^{7}$ formada por um grupo de pesquisadores dessa cidade alemã, por sinal, a mais judia da Alemanha, criando o Instituto de Pesquisa Social e a Revista de Pesquisa Social para a divulgação de suas produções. A pesquisa multidisciplinar, crítica, teórica, empírica e voltada para a emancipação coletiva dos sujeitos é a marca dos pesquisadores desde sua fundação. A Teoria Crítica, portanto, se caracteriza por uma teoria da sociedade acerca dos processos de (re)produção social que se manifestam nos fenômenos sociais, culturais, institucionais e políticos.

A perspectiva epistemológica da Teoria Crítica consiste na consolidação de uma teoria social que seja capaz de pensar criticamente as contradições e contestar as ideologias he-

6 "A expressão teoria crítica só aparece para designar o tipo de teoria que estava sendo desenvolvido pelos investigadores vinculados ao Institut für Sozialforschung [Instituto de Pesquisas Sociais] tardiamente, no conhecido escrito de Horkheimer intitulado Teoria tradicional e teoria crítica, publicado pela revista do Instituto em 1937. Antes disso, o autor designava sua teoria simplesmente como materialismo ou mesmo como filosofia social. De qualquer forma, o momento culminante para o começo da teoria crítica parece ser o ano de 1931, quando Horkheimer assume a direção do Instituto e propõe uma espécie de guinada nas pesquisas aí desenvolvidas, visível já em seu discurso de posse. Teoria crítica, portanto, aparece como um projeto, ou melhor, como um programa esboçado por meio de uma contraposição com aquilo que Horkheimer denominou então como teoria tradicional" (FLECK, 2017, p. 100).

7 Entre os membros, destacam-se Max Horkheimer (1895-1973), que foi diretor do instituto de 1930 até 1967 , Herbert Marcuse (1898-1979), Theodor Adorno (1903-1969), ingressou no Instituto no final dos anos 1930 e diretor de 1967 a 1969, Walter Benjamin (1892-1940), bolsista do Instituto no período de 1933-1940 e Jürgen Habermas (1929), filósofo e sociólogo, vivo e aposentado. Desde 2001, Axel Honneth (1949), filósofo e sociólogo, é o diretor do Instituto de Pesquisa social na atualidade. 
gemônicas, que Horkheimer chama de Teoria Tradicional. Tal questão demanda a revisão e atualização constante da função social da ciência, da sociedade e suas interfaces com a educação. Existem hoje diversas abordagens do objeto social, com enfoques em diferentes áreas, tais como: Filosofia, Sociologia, Ciência Política, Psicanálise, Literatura, Direito e Educação. A respeito da educação, Adorno (1995a) afirma que o compromisso social da escola está em dialogar sobre os problemas sociais e promover a reeducação das pessoas, no sentido de que os professores possam resistir às diversas formas de violência, pensadas na reflexividade do cotidiano escolar, pela postura autocrítica própria do conhecimento pedagógico, visando a construção de uma sociedade que pensa sobre si em meio às linguagens correntes, projetando nesse movimento formativo um futuro próspero à vida em sociedade.

Enquanto uma realidade severa e impiedosa, o exílio vivenciado por ambos os teóricos imersos em uma conjuntura social que acarretou a ruptura de padrões estabelecidos, ocasionou uma nova compreensão de mundo, das diferenças, da alteridade e da própria condição humana. Além disso, permitiu a percepção crítica de que muitas das ações coletivas apresentadas no contexto totalitário do Holocausto não foram oriundas de uma postura pessoal e livre dos sujeitos, mas da imposição e manipulação oriunda de um sistema coercitivo. Perius (2006, p. 17) afirma que:

A iminência da guerra e as perseguições sofridas (por serem judeus), o fracas-
so da revolução socialista na União Soviética, tornando-a mais um modelo de
totalitarismo e de violência e, por fim, a superficialidade da cultura de massas,
observada nos EUA na época do exílio, são alguns dos fatores mais determi-
nantes desse olhar crítico e da gênese de conceitos como o de 'totalidade social
falsa', 'sociedade administrada' ou, como aparece no texto Dialética do Escla-
recimento, 'calamidade triunfal' (triumphalen Unheils).

Contudo, o exílio não provoca somente o afastamento do sujeito da realidade primeira, mas o coloca em pleno contato com a nova realidade a qual ele passa a se inserir. Adorno vivenciou, por um lado, a barbárie causada pelo totalitarismo alemão, e por outro, a influência da cultura de massa sobre os sujeitos nos Estados Unidos. Adorno e Horkheimer, em 1941, partem então para Los Angeles. Foi a partir desse contexto de nazismo e do exílio que juntos redigem sua principal obra, Dialética do Esclarecimento (1944), cunhando o termo de indústria cultural. Os autores compreendem que a indústria cultural visa à homogeneização da sociedade e difunde a banalização da barbárie, pois não é necessário o encontro com o sofrimento e a dor do outro, somente que aceitemos e consumimos o que a nós é friamente arquitetado. A indústria cultural apresenta aos seus telespectadores uma realidade ilusória, bloqueando outras formas de conhecimento pelo fetiche da produtividade conduzida pela economia de mercado, que atualmente atinge uma dominação planetária (HABOWSKI; CONTE; BRANCO, 2019).

Mas não há como fugir dessa reprodução sem contestação, pois aquele que destoa ou não se mostra condizente com o padrão de vida estipulado é renegado e se torna excluído socialmente, já que vive à margem da cultura funcionalista das grandes massas. "Quem não se adapta é massacrado pela impotência econômica que se prolonga na impotência espiritual do isolado. Excluído da indústria, é fácil convencê-lo de sua insuficiência" (ADORNO, 
2009, p. 16). O sujeito caminha incessantemente em diversas presunções adulteradoras e desumanizantes, da qual a essência humana progressivamente se torna refém. Desse modo, Adorno (1995) defende que é urgente uma reeducação frente à banalização da vida colonizada por comportamentos violentos, para romper com a legitimação da barbárie humana provocada, em parte, pela reprodução da indústria cultural inquestionada e irrefletida socialmente (HABOWSKI; CONTE; BRANCO, 2019).

\footnotetext{
Suspeito que a barbárie existe em toda a parte em que há uma regressão à violência física primitiva, sem que haja uma vinculação transparente com objetivos racionais na sociedade, onde exista, portanto, a identificação com a erupção da violência física. Por outro lado, em circunstâncias em que a violência conduz inclusive a situações bem constrangedoras em contextos transparentes para a geração de condições humanas mais dignas, a violência não pode sem mais nem menos ser condenada como barbárie (ADORNO, 1995, p. 159-160).
}

Ante a essas realidades, Adorno aprimora a questão da dialética negativa, que se refere à crítica a positividade sintética presente na dialética inaugurada por Platão e que encontra em Hegel seu representante principal. Assim, a impossibilidade de síntese é o que marca a dialética adorniana, somado ao fato de que, nessa matriz teórica, a realidade não se identifica com o conceito e que por isso é negativa. A partir daí, manifestou em seus escritos a necessidade de uma educação que seja autocrítica e emancipadora, como uma das formas para que a barbárie humana não se repita, anunciando assim, a reeducação como o último reduto possível frente ao império da indústria cultural. Contudo, o exílio de Adorno não aconteceu apenas pela sua posição crítica diante das barbaridades realizadas pelo Estado nazista, mas também por ser judeu. Em Adorno vemos um inimigo do sistema nazista, já que a sua procedência etno-religiosa o colocava em posição de risco. Assim, em alguns de seus aforismos, publicados em sua obra biográfica, Mínima Moralia (primeira publicação em 1951), vemos relatos dos sentimentos oriundos de uma experiência de exílio - Reflexões de uma vida mutilada, que apesar de sua negatividade, por obrigá-lo a se refugiar em outra nação, permite romper fronteiras e analisar a situação social alemã sob uma nova perspectiva. De acordo com Ribeiro (2011, p. 154):

Assim, para Adorno, colocar-se fora de casa é o imperativo moral para que se proceda à constatação de que "todas as avaliações são falsas", que jamais se daria se não no exílio, a morada, por excelência do intelectual, ou melhor, sua não-morada, seu desabrigo, a frenética alternância do olhar e a conquista de outro ponto de vista capaz de ver o que comumente não se via. O preço a se pagar é o de uma vida austera, sem facilidades. Seu olhar diferenciado é fruto unicamente de sua experiência de vida radicalmente prejudicada.

A partir da perspectiva empírica, Adorno compreende que precisamos resistir individualmente contra a barbárie, no caso provocada pelo partido nazista e que ocasiona violências, extermínios, exílios, ondas de massas e de fanatismos em nome da autoridade e do convencimento pela palavra, de modo que o sofrimento alheio não incida na indiferença humana. Adorno (1993, p. 10) diz: "em face da concórdia totalitária que apregoa ime- 
diatamente como sentido a eliminação da diferença, é possível que, temporariamente, até mesmo algo da força social de libertação tenha-se retirado para a esfera individual". Tal perspectiva anuncia e considera a morte do que estamos vivendo conscientemente pelo isolamento que destrói a capacidade humana de agir voltada para o bem comum da vida em sociedade. Em seu aforismo Opinião de diletante, Adorno (1993, p. 70) afirma que "a barbárie é realmente o todo e triunfa ainda sobre o seu próprio espírito", pois constata que a violência destrói a vida humana e contrasta com uma ética da alteridade.

A coisificação do sujeito em conformidade ao fascismo ou a ordem totalitária, como vista no Holocausto, conduziu a sociedade para a sua deterioração, pondo a ignorância em ação. As violências sofridas nos campos de concentração no contexto da Segunda Guerra Mundial, de acordo com Adorno, não devem ser esquecidas, para que não corramos o risco de repetir esse processo desumanizador. O sentimento negativo de Adorno, fruto de um contexto de exílio, frente a uma sociedade destruída pelo fascismo, sobrevive no desejo de mudança e de repressão às diversas formas de violência contra a humanidade. As conjunturas de exílio conduziram Adorno a posicionar-se e se contrapor com duras críticas aos preconceitos, violências e barbáries, indo além de benefícios pessoais e procurando um comprometimento social com a existência humana pelo poder da educação. Ribeiro (2011, p. 171) reforça que:

\footnotetext{
O olhar do deslocado como descreve Adorno em Mínima Moralia expressa um ganho ao pensamento crítico se o intelectual exilado consegue manter-se austero em face de um redemoinho de pessoas, lugares, ambientes, apelos, aparências, ameaças, facilidades, inadaptações, negociações nas quais se vê envolvido. A perspectiva crítica, a reserva intelectual, a coragem moral são virtudes potentes a serem cultivadas pelo pensador no exílio.
}

Adorno (1995) foi contundente ao ressaltar que o único modo de esclarecimento das consciências contra a barbárie é a educação no contexto das massas populares. Vale destacar que a regressão humana se constituiu por mecanismos como a frieza, a repressão do medo, a dominação, a crueldade, a dureza de vida, características dos campos de concentração. Auschwitz representou uma espécie de racionalização instrumental centralizada pelos meios bárbaros despertados por ela mesma. Uma identidade autorreferente, não produtiva, porque é baseada na fraqueza do eu para o tempo, na história e no espaço, na reação ao diferente.

Adorno contribuiu para desvendar os determinantes da limitação do esclarecimento, da experiência do insucesso da humanização do mundo, da generalização da alienação e da dissolução da experiência formativa. Tal análise revela que as relações sociais não afetam apenas as condições da produção econômica e material, mas também interagem no plano da "subjetividade", onde originam relações de dominação. Adorno e Horkheimer (1985) realizaram uma crítica ao processo de esclarecimento por meio da razão, que fracassou e nos conduziu às mais catastróficas barbáries.

No sentido mais amplo do progresso do pensamento, o esclarecimento tem perseguido sempre o objetivo de livrar os homens do medo e de investi-los na posição de senhores. Mas a terra totalmente esclarecida resplandece sob o signo de uma calamidade triunfal. O programa do esclarecimento era o desencantamento do mundo. Sua meta era dissolver os mitos e substituir a imaginação pelo saber (ADORNO; HORKHEIMER, 1985, p. 13). 
Assim, sujeitos que se enquadram cegamente em coletivos convertem a si mesmos, aquilo que Adorno denominou de caráter manipulador, que é a incapacidade de levar a cabo experiências humanas, pela ausência de emoções. Na relação atual com a técnica, ao mesmo tempo em que a sociedade progride, os sujeitos podem regredir em irracionalismo patogênico. Para Adorno, se os sujeitos não fossem indiferentes em relação ao que acontece com os outros sujeitos, então Auschwitz não teria acontecido, pois a sociedade não teria aceitado. Adorno pensa a educação como um meio para desbarbarizar a sociedade, tendo seu pleno sentido quando orientada a uma autocrítica. Compreende que a exigência que Auschwitz não se repita é essencial, no sentido de que a educação se torne significativa quando trabalha com a inconsciência dessa agressividade, esclarecendo os mecanismos repressivos a partir da autorreflexão e da problematização do existente (HABOWSKI; CONTE; FLORES, 2018). Segundo Adorno (1995, p. 142), a educação após Auschwitz se encarregaria de duas questões básicas para que não recaísse na barbárie, a saber, a educação infantil, sobretudo na primeira infância, e o esclarecimento geral, que produz um clima intelectual, cultural e socialmente libertador da "produção de uma consciência verdadeira", pois "a tentativa de superar a barbárie é decisiva para a sobrevivência da humanidade" (ADORNO, 1995, p. 165).

Com a educação contra a barbárie no fundo não pretendo nada além de que o último adolescente do campo se envergonhe quando, por exemplo, agride um colega com rudeza ou se comporta de um modo brutal com uma moça; quero que por meio do sistema educacional as pessoas comecem a ser inteiramente tomadas pela aversão à violência física (ADORNO, 1995, p. 165).

Coerente com sua filiação à teoria crítica, Adorno ${ }^{8}$ teria revelado seu posicionamento a favor de uma tarefa da escola orientada para a formação de sujeitos com capacidade de autonomia (expressão kantiana) de pensamento e de ação. Entender o que Adorno via no sistema de ensino daquele tempo não é apenas ver sua crítica a uma instituição que propagava os sistemas de dominação na sociedade capitalista. Mas, também, compreender a visão do autor, sustentada pela perspectiva de escola como a instituição social capaz de formar e reeducar o homem das amarras da dominação inerentes à ordem capitalista. Escreveu teses sobre a necessidade que a sociedade tem de produzir comportamentos humanos que sirvam à manutenção do domínio econômico estabelecida historicamente. "Na sociedade capitalista, produzir para necessidade em sua forma mediada e, assim, fixada pelo mercado é um dos principais meios de forçar os seres humanos a fazer o que lhe é imposto" (ADORNO, 2015, p. 234).

Contudo, a única concretização efetiva de emancipação consiste em que aquelas poucas pessoas interessadas nessa direção, muitas vezes exiladas dos contextos de origem, orientem toda a sua energia para que a educação aconteça a partir da contradição e da resistência aos dispositivos de controle, que asseguram a reprodução do desprezo social já

8 Após um período de dezesseis anos no exílio, Adorno e Horkheimer retornaram para a Alemanha e reconstruíram o Instituto de Pesquisa Social em seus fragmentos, uma vez que se encontrava arruinado. Adorno morreu em 1969, na Suíça, mas deixou um vasto legado na reflexão crítica contra a barbárie e contra uma sociedade massificadora, que coisifica o ser pela ausência de emoções e pela indiferença à alteridade. 
existente. Assim como apontam, em certo sentido, as notas marginais para o significado do exílio que fez surgir o movimento de fortalecimento da Teoria Crítica.

\begin{abstract}
Como se sabe, a teoria crítica se formou no exílio norte-americano - contra ambos, a sociedade capitalista, a qual deixou o fascismo surgir, bem como, contra o marxismo soviético, que levou à ditadura sobre o proletariado. Ela saiu do exílio somente por poucos anos para o centro das atenções global e se tornou a fonte de inspiração para o movimento de protesto que penetrou o mundo ocidental inteiro. Isto aconteceu entre os anos 1964 até 1970. Nessa época, Marcuse e Adorno eram famosos. Depois disso, a Teoria Crítica não era mais considerada contemporânea, mas como algo excessivamente radical, um impasse teorético. Um linguisticturn devia fazê-la anexável ao discurso predominante das ciências sociais e da teoria da democracia. Nessa forma linguisticamente mudada ela também chegou ao Brasil. Adorno, Horkheimer, Marcuse e Benjamin foram lidos, através da visão de Habermas, de como eles seriam os precursores inadequados da sua teoria da comunicação (TÜRCKE, 2018, p. 325).
\end{abstract}

Tudo indica que em grupos de exilados se produzem trabalhos (do estado de exílios) e isso fortalece os movimentos que levam à cultura do diálogo, criando uma rede de leituras a respeito dos processos de civilização e barbárie. Sem sombra de dúvidas, "a nossa política não conhece hoje outro valor (e, por conseguinte, outro desvalor) que a vida, e até que as contradições que isto implica não forem solucionadas, nazismo e fascismo, que haviam feito da decisão sobre a vida nua o critério político supremo, permanecerão desgraçadamente atuais" (AGAMBEN, 2004, p. 18). Hoje, as redes ao mesmo tempo em que aproximam e interconectam globalmente as pessoas acabam cerceando a capacidade de pensar acerca das informações instantâneas e bem-sucedidas, seguidamente marcadas por intrigas e boatos políticos que deixam os sujeitos desequilibrados, desorientados ou afogados na própria notícia falsa (fake news). Vale destacar o alerta de Türcke (2018, p. 327):

\footnotetext{
Quem caiu na rede pertence a uma força maior; então não anda mais com seus próprios pés. [...] Como nó na rede você não tem uma existência confortável. Pois a rede conecta cada nó com os outros, assim como os isola entre si. Onde a relação interpessoal não é mais íntima do que os nós da rede predominam a frieza, a venda da solidariedade e [a falta ou a venda de] amor ao próximo.
}

A ditadura hoje é revelada pelo mercado e pela palavra espalhada em rede, sem uma educação de valores, que confunde, impacta e gera a incapacidade de pensar sobre a própria condição humana, visto que a sociedade criou uma rede (aprisionamento) de mútua e contínua dependência, cujas mídias se alimentam do ofuscamento da realidade pela desinformação socializada (de regressão e alienação humana) e propagam aos sujeitos que eles só conseguem ser livres se estiverem interconectados. E isso acontece em todas as esferas da vida humana, atingindo inclusive os espaços educativos, dispensando o potencial libertador no trabalho de desenvolvimento humano devido à condição social limitante da ação do professor.

Se as pessoas pudessem decidir sobre si mesmas e sobre suas vidas, se não estivessem encerradas no sempre-igual, então não se entediariam. Tédio é o 
reflexo do cinza objetivo. Ocorre com ele algo semelhante ao que se dá com a apatia política. A razão mais importante para esta última é o sentimento, de nenhum modo injustificado das massas, de que, com a margem de participação na política que lhes é reservada pela sociedade, pouco podem mudar em sua existência, bem como, talvez, em todos os sistemas da terra atualmente. O nexo entre a política e os seus próprios interesses lhes é opaco, por isso recuam diante da atividade política. [...] Em íntima relação com o tédio está o sentimento, justificado ou neurótico, de impotência: tédio é o desespero objetivo (ADORNO, 1995, p. 76).

Há uma impotência do sujeito diante das contradições objetivas da realidade, no sentido de desenvolver práticas repressivas a manifestações de professores, estudantes e servidores públicos, e supervalorizar a crítica a esses movimentos sociais, transformando-os em "pretexto ideológico para coação moral" (ADORNO, 1995a, p. 208). A denúncia de que vivemos em um mundo administrado, de que o sujeito é produto ideológico-moral "provocado pelo estado de forças produtivas técnicas, estado que, ao mesmo tempo, o condena à ilusão", é cada vez mais atual (ADORNO, 1995a, p. 217).

\section{A Ditadura Militar e o autoritarismo na Perspectiva de Paulo Freire}

Paulo Freire (1921-1997), nascido em 19 de setembro de 1921 em Recife, Pernambuco, é considerado um dos pensadores mais notáveis da educação, pois dedicou grande parte de sua vida ao reconhecimento do valor da educação para uma sociedade emancipada, bem como no combate às formas de pedagogia bancária, excludente e elitista. A educação se tornou, aos seus olhos, um instrumento de libertação e emancipação dos povos, das gentes. Suas reflexões tiveram incidência na sociedade brasileira na época de transição para a modernização, onde as disputas pelo poder político estavam centradas em duas grandes forças: urbano-industrial e agrocomercial. Estas foram as bases de 1955 a 1965 que propunham uma ideologia da consciência nacional, sugerindo o desenvolvimento do país.

Paulo Freire expôs que é necessário aumentar o grau de atuação política da massa sobre as questões que estão ocorrendo na sociedade, para o desenvolvimento de um discurso crítico necessário à interpretação da realidade e para a participação na vida pública. Freire acreditava que a libertação do sujeito oprimido seria possível, por meio de uma educação problematizadora da realidade, alicerçada em perguntas provocadoras de inquietações e diálogos críticos na tomada de posição linguística a respeito da vida coletiva. Para isso, sugeriu como potencial para uma pedagogia da autonomia o círculo de cultura, pois em cada corpo social existem temas geradores para serem discutidos, destacando-se a compreensão pela leitura crítica do passado, não como simples repetição, mas como participação democrática no sentido presente, alargando horizontes de conhecimento do período histórico e do contexto social. Ou seja, para Freire compreender é participar num sentido, numa tradição, numa conversa, fazendo que a nossa realidade seja enriquecida com novas compreensões encontradas na linguagem e na capacidade de agir no mundo (HABOWSKI; JACOBI; CONTE, 2018).

A Ditadura Militar do Brasil ocorreu de 1964 a 1985, momento em que os militares governaram o país, caracterizado pela ausência de democracia, destruição dos direitos 
constitucionais, censuras, perseguições políticas e sentenças aos que eram contrários ao autoritarismo, deixando estragos no sistema educacional e na história nacional. No período de 1930 a 1964 Paulo Freire se destacou entre os intelectuais brasileiros, tornando-se reconhecido desde o governo do presidente João Goulart, ao passo de ter coordenado o Programa Nacional de Alfabetização (PNA, em 1962). Freire elaborou os alicerces de seu raciocínio, sempre ligado ao contexto sociopolítico brasileiro, vigilante às dificuldades da população, principalmente na busca de respostas democráticas voltadas aos oprimidos enquanto atitude crítica frente ao mundo.

Esse trabalho intelectual em prol dos mais necessitados foi obstruído pelo Golpe Militar de 1964, pois mobilizava a classe oprimida a lutar por seus direitos e liberdade de expressão. Tal ato, frente a uma época de enfrentamentos para a história do Brasil, culminou no exílio de muitos intelectuais, bem como, de Paulo Freire. Através do golpe de estado, "os ideais políticos advindos do PNA foram imediatamente suspensos, seus/suas mentores/ as procurados/as, tendo seus direitos constitucionais caçados e, muitas vezes, sendo exilados/as, como foi o caso de Paulo Freire" (SILVA, 2011, p. 51). Nesse contexto, a sociedade capitalista brasileira apresentava-se uma sociedade:

[...] fechada a que já nos referimos. Sociedade, acrescente-se, com o centro de decisão de sua economia fora dela. Economia, por isso mesmo, comandada por um mercado externo. Exportadora de matérias primas. Crescendo para fora. Predatória. Sociedade reflexa na sua economia. Por isso alienada. Objeto e não sujeito de si mesma. Sem povo. Antidialogal, dificultando a mobilidade social vertical ascendente. Sem vida urbana ou com precária vida urbana. Com alarmantes índices de analfabetismo, ainda hoje persistentes. Atrasada. Comandada por uma elite superposta a seu mundo, ao invés de com ele integrada (FREIRE, 2009, p. 57).

Visando não findar suas críticas que emergiam de uma realidade degradante, em prol de um povo oprimido por um sistema totalitário de governo, em junho de 1964, antes de ser preso pela primeira vez, Freire solicitou permissão do passaporte para viajar ao México. Porém, a solicitação foi recusada pelos políticos que invalidaram seus direitos, alegando que seus estudos são esquerdistas ao privilegiar os mais necessitados da sociedade. Na primeira prisão, Freire permaneceu por vinte dias, sendo solto no dia 3 de julho. Na segunda prisão, ficou preso por cinquenta dias, passando por diversos presídios de Recife e Olinda. Quando solto, Freire viajou ao Rio de Janeiro sendo recomendado para pedir acolhimento na embaixada boliviana, chegando a La Paz com seus familiares em outubro de 1964. Porém, aí ficou menos de dois meses, pois um novo golpe de Estado o atacou, precisando se exilar no Chile. Durante o exílio no Chile, escreveu o livro Pedagogia do Oprimido. No período de abril de 1969 a fevereiro de 1970, Freire lecionou nos Estados Unidos, na Universidade de Harvard. Posteriormente, no período de 1970 a 1980, exilou-se em Genebra, Suíça. A partir de 1975, quando conheceu Guiné-Bissau (África), Freire trabalhou mais diretamente na África, mais especificamente em Cabo Verde, Angola, São Tomé e Príncipe, que estavam em um período de reconstrução, pela conquista da independência. Freire só retornou ao Brasil no final de 1980. Por esses caminhos, Freire (2003, p. 34) escreveu sobre a experiência do exílio: 
Na verdade, um dos sérios problemas do exilado ou exilada está em como lidar, de corpo inteiro, com os sentimentos, desejos, razão, recordação, conhecimento acumulados, visões de mundo, com a tensão entre o hoje vivido na realidade de empréstimo e o ontem, no seu contexto de origem, de que chegou carregado de marcas fundamentais. No fundo, como preservar sua identidade na relação entre a ocupação indispensável no novo contexto e a pré-ocupação em que o de origem deve constituir-se. Como lidar com a saudade sem permitir que ela vire nostalgia.

O exílio marcou profundamente suas reflexões. Paulo Freire, mesmo com tamanha capacidade intelectual, não teria tal abordagem questionadora da realidade sem a experiência do exílio. Suas críticas e manifestações adquiriram forma e consistência na medida em que esteve inserido nos contextos de expatriação. Por isso, publicou diversas obras que refletiam suas experiências no Brasil e suas vivências nômades de exilado político. Da vivência comprometida com os oprimidos, Freire construiu suas reflexões percebendo as incoerências e obstáculos do processo emancipador e os mecanismos de dominação e de poder, para manter a opressão em relação aos dominados. Freire provocou hipóteses transformadoras sobre a práxis social crítica mediada pelo diálogo, articulando as dimensões objetiva, subjetiva e social da racionalidade educativa, pela capacidade de leitura crítica de mundos e pela abertura realizada num contexto sociocultural com os outros (marginalizados e oprimidos).

Na concepção freireana, é por meio da relação de diálogo que se inicia o ato de ensinar e de aprender com atividades participativas de pesquisa e de (re)elaboração própria e coletiva, nas quais podemos ser autônomos e motivados a (re)conhecer ações, interpretações, como atores do conhecimento social. A autonomia faz parte dos processos educativos e formativos, ao lado da capacidade de (auto)crítica, de ajudar os estudantes a desenvolverem o gosto de fazer leituras, interpretações e relações com os outros. Esse diálogo não pode reduzir-se a uma postura de impor ideias ou apenas trocá-las, ou seja, "o diálogo não pode converter-se num bate-papo desobrigado que marche ao gosto do acaso entre professor ou professora e educandos. O diálogo pedagógico implica tanto o conteúdo ou objeto cognoscível" (FREIRE, 2003, p. 118).

Mas em uma sociedade opressora, como no seu contexto de exílio, as possibilidades de diálogo são atrofiadas ou diminuídas em informações desconexas e sem sentido, pois só ocorre "entre iguais e diferentes, nunca entre antagônicos" (FREIRE, 2002, p. 123). A ideia da educação problematizadora estimula nos estudantes a capacidade de (re)pensar por intermédio de problematizações e contextualizações, de buscas por respostas diferentes à educação tradicional chamada por Freire de bancária, de saberes prontos, com perguntas e respostas lineares, não possibilitando novos e diferentes significados e sentidos. A problematização pode partir do professor e do estudante, porém, precisa ser retroalimentada para o aperfeiçoamento das performances, mas sempre em profícuos diálogos com as diferenças.

Freire dedicou grande parte de sua vida ao reconhecimento da educação para uma sociedade emancipada, bem como, no combate às formas de pedagogia bancária, excludentes, preconceituosas e elitistas. Suas reflexões tiveram incidência na sociedade brasileira na época de transição para a modernização, onde as disputas pelo poder político estavam centradas em duas grandes forças: urbano-industrial e agro comercial. Estas foram as ba- 
ses de 1955 a 1965 que propunham uma ideologia da consciência nacional, sugerindo o desenvolvimento do país. Paulo Freire expõe que é necessário aumentar o grau de atuação política do povo acerca das questões que acontecem no âmbito social, enquanto seres voltados à construção emancipatória. Para isso, sugere como potencial do círculo de cultura, pois em cada âmbito social existem temas geradores para serem discutidos, destacando-se a compreensão pela leitura crítica dos clássicos, não como simples repetição, mas como participação no presente, alargando horizontes de conhecimento do período histórico e do contexto social. Para que o círculo de cultura vingasse, era preciso realizar pesquisas por meio de temas geradores com conversas informais com os moradores da localidade, em que "dirão o porquê, e como e o para que da investigação que pretendem realizar e que não podem fazê-lo se não se estabelece uma relação de simpatia e confiança mútuas" (FREIRE, 2002, p. 121). Os pesquisadores em seus diálogos com a população acionam um olhar crítico, recolhendo subsídios para a compreensão dos modos de vida, de ser e de pensar dos sujeitos, a fim de que juntos possam tecer a sua descodificação, através de uma visão crítica, reflexiva, relacional e observadora da própria realidade.

Ao invés de manifestar uma perspectiva fatalista ou de acomodação intelectual em relação ao exílio, Freire luta e desenvolve nessa experiência uma sensibilidade, generosidade e solidariedade aos diferentes contextos, tornando-se um educador mundialmente reconhecido por promover uma cultura do diálogo mediante a conscientização. A partir do diálogo intercultural, Freire conseguiu (re)aprender, questionar e dizer a própria palavra, pois "foi por esses pedaços de mundo, como exilado, que pude compreender melhor o meu próprio país. Foi vendo-o de longe, foi tomando distância dele que eu entendi melhor a mim mesmo" (FREIRE; FAUNDEZ, 1985, p. 22). Freire (2002, p. 38) afirma que é a "reflexão e a ação dos homens sobre o mundo que faz a transformação acontecer, sem esses dois atos a superação da condição opressor e oprimido é impossível”. Said (2003, p. 58) destaca que:

\footnotetext{
O exilado sabe que, num mundo secular e contingente, as pátrias são sempre provisórias. Fronteiras e barreiras, que nos fecham na segurança de um território familiar, também podem se tornar prisões e são, com frequência, defendidas além da razão ou da necessidade. O exilado atravessa fronteiras, rompe barreiras do pensamento e da experiência.
}

O exílio trouxe sofrimento para Freire, mas também experiências que o enriqueceram como intelectual da classe trabalhadora nas instituições de diferentes países, cultivando assim uma forma de ensinar e de aprender que humaniza por meio da reflexão e da prática social, denunciando as falsas fronteiras do conhecimento. Desse modo, Freire destaca que as massas oprimidas devem se introduzir criticamente no meio através da práxis, o que induzirá o sujeito a ser sujeito da história, pois "transformar a realidade opressora é tarefa histórica, é tarefa dos homens" (FREIRE, 2003, p. 41). Afinal, o diálogo também abre possibilidades para a utopia esperançosa, visto que não há diálogo sem a esperança que acompanha a busca de mudanças para a melhoria da vida em sociedade. Nas palavras de Freire (2002, p. 95), "movo-me na esperança enquanto luto e, se luto com esperança, espero", não de forma ilusória, pacífica e receptora, mas com a disposição de saber debater proposições e reconstruí-las permanentemente conforme as necessidades, por intermédio da geração de 
uma reflexividade que provém do outro (nem sempre disponível), pois, "não há o diálogo verdadeiro se não há nos seus sujeitos um pensar verdadeiro".

\section{CONSIDERAÇões FINAIS}

Adorno e Freire vivenciaram o exílio em períodos, locais e ocasiões diferentes, mas ambos vivenciaram tempos de inquietações diferentes e incertezas, desenvolvendo modelos críticos a regimes totalitários que assolavam suas pátrias, contra a identificação cega aos coletivos, o poder dominador de manipular e homogeneizar os diálogos de culturas, que voltou com ainda mais força e dispersão com as mídias eletrônicas da atualidade. Cabe destacar que esses intelectuais apresentam realidades, conjunturas políticas e sociais distintas, bem como compreensões sobre educação e emancipação com semelhanças. Ambos defendem a necessidade de questionar a sociedade (contraditória e conflitante), a constituição da formação humana dentro do processo social (caracterizada por hierarquias escolares e monólogos didáticos/bancários), além de incitarem a autorreflexão por meio do diálogo, do pensar crítico que não acontece na educação apenas pela capacidade subjetiva, mas exige a formação emancipatória dos conhecimentos coletivos (dialéticos, da curiosidade epistemológica). Ainda que ambos tenham surgido em contextos sociais e culturais distintos, ambos pensadores convergem em relação à educação como possibilidade de promover o esclarecimento coletivo. Adorno trata da crítica à sociedade administrada, da coisificação do ser e da cultura a ser superada pela educação, enquanto Freire aborda a emancipação política que a escola potencializa no sentido da superação do estado de opressão.

Adorno afirma que para superar as questões desagregadoras e os tempos sombrios da sociedade (marcados pela dor e injustiça), é necessário manter-se aberto ao outro, pelos sentidos educativos, e renovar os sentimentos de amor que nos une à cultura plural e aos contextos danificados. Freire, por sua vez, compreende que a educação é um caminho para conduzir o sujeito para a emancipação das consciências, que demanda a compreensão da significação profunda da palavra na práxis social (impossibilidade de neutralidade da ação pedagógica) e pelo diálogo entre prática e teoria para a educação libertadora do sentido educativo e humano. "Tanto Adorno quanto Freire combatiam a sociedade capitalista de seu tempo e ambos os autores se posicionavam contra a alienação do homem; logo, a emancipação humana foi preocupação comum" (MASHIBA, 2013, p. 8). Esse movimento do pensar os exílios tornou-se um ato humanamente revolucionário (a favor da vida) e de luta contra a violência, porque reconheceu os fatos que foram apagados pela tradição cultural que desconsidera a condição das vítimas e valoriza os vencedores. Adorno e Freire abrem diante de nós perspectivas de reconstrução epistemológica, política, cultural e social, por meio da educação, frente ao pensamento homogeneizador da cultura, possibilitando o reconhecimento dos mecanismos aprisionadores da vida, uma vez que o exílio implica a ruptura de absolutismos, assim como questionamentos da realidade.

Concluímos que esses pensadores, após vivenciarem suas experiências de exílio, projetam em suas teorias alicerces para refletirmos sobre as novas formas de violência social, colocando a educação no centro dessa reversão cultural, como um meio para desbarbarizar a sociedade, tendo seu pleno sentido quando dirigida à autocrítica, e nutrir o movimento de 
autorreflexão dialógica e de problematização do existente. Assim, a formação de uma consciência crítica acontece a partir da contradição e da resistência social, como um caminho à liberdade e abertura para o discurso alheio, que reconhece a pluralidade de percepções da realidade e reeduca as pessoas violentas.

\section{REFERÊNCIAS}

ADORNO, Theodor Ludwig Wiesengrund. Educação e Emancipação. Rio de Janeiro: Paz e Terra, 1995.

ADORNO, Theodor L. W. Notas marginais sobre Teoria e Práxis. In: ADORNO, T. L.W. Palavras e Sinais. Modelos críticos 2. Rio de Janeiro: Vozes, 1995a.

ADORNO, Theodor L. W. Ensaio sobre psicologia social e psicanálise, São Paulo: UNESP, 2015.

ADORNO, Theodor Ludwig Wiesengrund. Mínima moralia: reflexões a partir da vida danificada. Trad. Luiz Eduardo Bica, 2. ed. São Paulo: Ática, 1993.

ADORNO, Theodor Ludwig Wiesengrund. A atualidade da filosofia. Primeira Versão, Porto Velho, Ano IV, n. 195, p. 2-12, 2005. Disponível em: http://www.primeiraversao.unir.br/ atigos_pdf/195_.pdf. Acesso em: 15 nov. 2018.

ADORNO, Theodor Ludwig Wiesengrund; HORKHEIMER, Max. A Dialética do Esclarecimento. Rio de Janeiro: Jorge Zahar, 1985.

AGAMBEN, Giorgio. Homo Sacer. O poder soberano e a vida nua I. Trad. Henrique Burigo. Belo Horizonte: Editora UFMG, 2004.

ARENDT, Hannah. Origens do totalitarismo. Trad. Roberto Raposo. São Paulo: Companhia das Letras, 1989.

BENJAMIN, Walter. Obras escolhidas I: magia e técnica, arte e política. São Paulo: Brasiliense, 1994.

DEVECHI, Catia Piccolo Viero; TREVISAN, Amarildo Luiz. Sobre a proximidade do senso comum das pesquisas qualitativas em educação: positividade ou simples decadência? Revista Brasileira de Educação, v. 15, n. 43, p. 148-161, jan./abr. 2010.

FLECK, Amaro. Afinal de contas, o que é teoria crítica? Princípios: Revista de Filosofia, Natal, v. 24, n. 44, p. 97-127, 2017. 
FREIRE, Paulo. A educação na cidade, 5. ed. São Paulo: Ed. Cortez, 2001.

FREIRE, Paulo. Pedagogia da Esperança: um reencontro com a Pedagogia do Oprimido, 11. ed. São Paulo: Paz e Terra, 2003.

FREIRE, Paulo. Extensão ou Comunicação? 11. ed. Rio de Janeiro: Paz e Terra, 2006.

FREIRE, Paulo. Pedagogia do oprimido, 34. ed. Rio de Janeiro: Ed. Paz e Terra, 2002.

FREIRE, Paulo. Educação como prática da liberdade. Rio de Janeiro: Paz e Terra, 2009.

FREIRE, Paulo; FAUNDEZ, Antonio. Por uma pedagogia da pergunta. Rio de Janeiro: Paz e Terra, 1985.

GAMBOA, Sílvio Ancisar Sánchez. Pesquisa em Educação: métodos e epistemologias. Chapecó: Argus, 2008.

HABERMAS, Jürgen. Dialética e Hermenêutica: para a crítica da hermenêutica de Gadamer. Trad. Álvaro L. M. Valls. Porto Alegre: L\&PM, 1987.

HABOWSKI, Adilson Cristiano; CONTE, Elaine; FLORES, Helen Rose Flores de. Educação e violência na teoria crítica de Adorno. Fragmentos de Cultura, Goiânia, v. 28, n. 2, p. 231-245, jan./mar. 2018. DOI: 10.18224/frag.v28i2.6440

HABOWSKI, Adilson Cristiano; CONTE Elaine; BRANCO, Lilian Soares Alves. A violência institucionalizada pela Indústria Cultural: debates educativos. Revista Internacional de Educação Superior, Campinas, v. 4, n. 2, p. 481-498, fev. 2018. DOI: 10.22348/ riesup.v4i2.8651336

HABOWSKI, Adilson Cristiano; JACOBI, Daniel Felipe; CONTE, Elaine. Garimpando ideias para a reconstrução do Círculo hermenêutico e do círculo de cultura. Revista Teias, Rio de Janeiro, v. 19, n. 53, p. 275-287, abr./jun. 2018. DOI: 10.12957/teias.2018.29719

JENSEN, Silvina; PARADA, Mauricio. Exílio e afastamento: considerações sobre uma hermenêutica da distância? Tempo, Niterói, v. 25, n. 2, p. 405-410, 2019. Disponível em: http://www.scielo.br/pdf/tem/v25n2/1980-542X-tem-25-02-405.pdf Acesso em: 15 dez. 2019. MASHIBA, Glaciane Cristina Xavier. Emancipação humana em Theodor Adorno e Paulo Freire, 2013, 150s. Tese (Doutorado em Educação) - Universidade Estadual de Maringá, Maringá, 2013.

MÜLLER-Doohm, Stefan. En tierra de nadie. Theodor W. Adorno: una biografia intelectual. Barcelona: Herder, 2003. 
PERIUS, Oneide. Esclarecimento e dialética negativa: sobre o além-do-conceito em Theodor Adorno, 2006, 113 p. Dissertação (Mestrado em Filosofia) - Pontifícia Universidade Católica do Rio Grande do Sul, Porto Alegre, 2006.

PUCCI, Bruno. Filosofia negativa e Educação: Adorno. Filosofia, sociedade e educação, Marília, v. 1, n. 1, p. 163-192, 1997.

RIBEIRO, Adelia Maria Miglievich. Intelectuais no exílio: onde é a minha casa? Dimensões, Espírito Santo, v. 26, p. 152-176, 2011.

SAID, Edward. Reflexões sobre o exílio e outros ensaios. Trad. Pedro Maia Soares. São Paulo: Companhia das Letras, 2003.

SILVA, Alexandre Rodrigo Nishiwaki da. Conhecimento e conscientização: a historicidade do pensamento de Paulo Freire, 2011, 142s. Dissertação (Mestrado em Ciências Humanas) - Universidade Federal de São Carlos, São Carlos, 2011.

SZNITER, Célia. A Dimensão Visual da Propaganda Nazista: as imagens do judeu e do ariano, 1996, 175 p. Dissertação (Mestrado em Letras Orientais) - Universidade de São Paulo, São Paulo, 1996.

TÜRCKE, Cristoph. Carta para o grande cacique da teoria crítica paulista. In: ZUIN, Antonio A. S. et al. (Org.). Teoria crítica, formação cultural e educação: homenagem a Bruno Pucci. Piracicaba: Editora Unimep, 2018, p. 325-327.

\section{DADOS DOS AUTORES:}

\section{Adilson Cristiano Habowski}

Doutorando em Educação pela Universidade La Salle/UNILASALLE. Canoas/RS - Brasil. Membro do Núcleo de Estudos sobre Tecnologias na Educação - NETE/UNILASALLE/ CNPq. adilsonhabowski@hotmail.com

\section{Elaine Conte}

Doutora em Educação pela Universidade Federal do Rio Grande do Sul (UFRGS). Professora do Programa de Pós-Graduação em Educação da Universidade La Salle/UNILASALLE, Canoas/RS - Brasil. elaine.conte@unilasalle.edu.br

Submetido em: 16-12-2018

Aceito em: 23-12-2019 